\title{
O ENSINO DA HISTÓRIA NOS CURSOS DE GRADUAÇÃO EM EDUCAÇÃO FÍSICA
}

\author{
Prof. Dr. Victor Andrade de Melo
}

Resumos: Este artigo objetiva, a partir de uma determinada compreensão de formação profissional, argumentar sobre a importância da disciplina "História da Educação Física e do Esporte" nos cursos de graduação em Educação Física. Ao questionar seu atual modelo de ensino, pretende apresentar uma alternativa para potencializar a contribuição da disciplina para os estudantes.

Unitermos: Ensino da História; História da Educação Física e do Esporte

Porque temos que estudar história em um curso de graduação em Educação Física? É possível que essa pergunta já tenha sido por diversas vezes pronunciada entre alguns estudantes dos diversos cursos superiores ligados à formação do professor de Educação Física espalhados pelo Brasil.

Afinal, em que o estudo da história estaria a contribuir na formação e atuação do futuro professor? Haveria realmente espaço e necessidade de uma disciplina específica para estudos desta natureza? Esta reflexão, surgida no decorrer de minhas recentes experiências enquanto professor e pesquisador da disciplina "História da Educação Física e do Esporte", objetiva, a partir de uma determinada compreensão de formação profissional, argumentar sobre a importância dos estudos ligados à história para os estudantes de graduação e professores de Educação Física em geral.

Alguns argumentos podem ser levantados na tentativa de entender o que está em torno do questionamento inicial e de uma possível desvalorização da História nos cursos de 
graduação em Educação Física. Poderíamos, por exemplo, levantar o problema da afinidade da área de conhecimento. Argumentaria-se que aqueles que vêm cursar a graduação em Educação Física normalmente não se identificariam com disciplinas ligadas às ciências humanas/sociais, estando suas preferências voltadas às ciências exatas e/ou biológicas. Poderia-se também sugerir que significativa parte das faculdades/institutos de Educação Física estão ligados a centros/ departamentos da área biomédica e que normalmente os vestibulares para ingresso em tais instituições privilegiariam disciplinas como a Física, a Química e a Biologia.

Este seria, entretanto, um caminho bastante perigoso. Correríamos o risco de referendar uma visão pautada no senso comum, partindo de um antigo estereótipo de aluno que vem buscar os cursos superiores de Educação Física, e desconsiderando algumas importantes mudanças na formação do professor e no perfil do estudante da área, pronunciadamente perceptíveis nos últimos 10/15 anos.

Um outro caminho parece mais interessante, até por privilegiar discussões mais diretamente relacionadas ao assunto central deste texto. Os questionamentos, indubitavelmente, expressam um certo desconforto e refletem uma impressão geral de dúvida. $E$ de fato este não tem sido um assunto discutido prioritariamente: por que existem disciplinas diretamente ligadas à História em cursos de graduação em Educação Física?

Ao observarmos, por exemplo, os trabalhos constantes nas coletâneas dos congressos nacionais já realizados especificamente para discutir os aspectos históricos ligados à Educação Física e ao esporte, percebemos que bem poucos trabalhos se dedicam tal preocupação. A falta de discussões desta natureza não contribui, inclusive, no estímulo à busca de iniciativas ligadas ao redimensionamento do ensino da disciplina, além de corroborar com as inexatidões no que se refere à sua existência na estrutura curricular.

Basta ver, por exemplo, que, mais do que gostaríamos e 
embora existam louváveis exceções, o ensino da História nos cursos de Educação Física muitas vezes se resume a apresentação dos chamados "conteúdos clássicos". Apresentase uma série de nomes e fatos eleitos como relevantes, enquadrados no interior de períodos consagrados tradicionalmente e importados da história geral (Grécia Antiga, Roma, Idade Média etc.), a partir de uma ausente, confusa ou não consciente compreensão historiográfica. Ou, tão complicada quanto a abordagem anterior, estimula-se uma suposta crítica de alguns fatos, sem que se preocupe especificamente com a natureza de tal crítica e com sua adequação a uma disciplina que pretende trabalhar os aspectos históricos.

Isto não parece ser verdadeiro somente na realidade nacional. Roberta J. Park (1987) afirma que nos Estados Unidos, onde o estudo da História da Educação Física e do Esporte já está bastante avançado, os professores de Educação Física que se envolvem com a docência de disciplinas ligadas a esta sub-área de estudo não têm demonstrado conhecimentos metodológicos adequados. Park afirma ainda que tais professores acabam recebendo menores cobranças para melhoria de seus cursos, já que grande parte dos alunos está mais interessada em disciplinas ligadas a área biomédica. Esta situação se propaga por gerações, sem que a História venha a ser devidamente valorizada.

Enfim, os avanços recentes das pesquisas históricas na Educação Física e Esporte no Brasil ainda não parecem ter contagiado o contexto geral do ensino da História nos cursos de graduação, nem tampouco estimulado profusos debates acerca de seu espaço e "utilidade".

Tal espaço, então, tem se mantido simplesmente pela força da tradição. Isto é, pois sempre existiram disciplinas ligadas ao ensino da história nos diversos cursos de formação profissional na Educação Física brasileira no decorrer do tempo.

Ao observarmos um pouco da própria história desses cursos de formação, veremos que antes mesmo da efetivação 
do primeiro curso, em propostas que não passaram de projetos, já se pensava em uma disciplina específica para discutir os aspectos históricos da Educação Física e dos esporte. E ao observarmos, por exemplo, a grade curricular das pioneiras Escolas de Educação Física do Espírito Santo, de São Paulo e da Escola de Educação Física do Exército podemos confirmar tal assertiva.

Vamos tomar aqui um exemplo significativo: a situação da grade curricular na Escola Nacional de Educação Física e Desportos (ENEFD). Desde sua criação, em 1939, foi dedicada uma cadeira ao estudo da história. Compreendendo o contexto das disciplinas naquela Escola, podemos levantar o provável espaço, identificar o possível status e inferir sobre o significado daquela cadeira no âmbito da formação profissional na ENEFD.

Com a aprovação do regimento interno, em 1941, ficava referendada uma distinção clara entre cadeiras teóricas, onde se situava a cadeira de História, e cadeiras práticas. Deve-se observar que os professores das cadeiras teóricas deviam atender a algumas exigências dispensadas para os das cadeiras práticas. Além de terem nível superior, a grande parte das cadeiras teóricas somente poderia ser ocupada por médicos. Aliás, os primeiros professores da disciplina foram exatamente médicos: Orlando Eduardo Silva e Aloísio Aciolly.

É interessante ressaltar que um prestígio diferenciado era destinado às cadeiras, gozando de maior prestígio as cadeiras teóricas, destacadamente as médicas. Assim, a cadeira de 'História e Organização da Educação Física e Desportos' ocupava um lugar e gozava de um prestígio intermediário, já que embora fosse teórica, era não-médica.

Independente da flagrante dicotomização teoria-prática, as disciplinas tinham em comum o fato de serem orientadas diretamente para a formação de um profissional inicialmente considerado mais como um técnico do que como um professor (FARIA JÚNIOR,1987). As disciplinas estavam preocupadas em apresentar verdadeiros modelos de atuação, que tivessem 
utilidade operacional técnica direta. A partir desta compreensão, é possível inferir que o prestígio da cadeira de História reduziase, por ser considerada de uma "utilidade prática menor".

Curioso observar como tal representação ficava denotada mesmo em algumas falas dos professores da cadeira. No relatório da cadeira de 'História e Organização da Educação Física' referente ao primeiro ano de existência da ENEFD, o professor Orlando Eduardo Silva, primeiro professor da disciplina, afirma em certo momento (apud PINTOR, 1996): "Embora não constituindo matéria essencial à formação dos diferentes especialistas...".

É provável que reflexos desta situação ainda sejam notáveis. Qual é a "aplicabilidade"da História da Educação Física e do Esporte? Aquele aluno que se interessar mais diretamente pela atuação escolar, vai procurar e encontrar em cadeiras ligadas à pedagogia indicadores para uma "aplicação prática" melhor. Aqueles que se interessarem pelo treinamento desportivo, podem encontrar na Fisiologia, na Biomecânica, entre outras, caminhos para uma "prática efetiva". Mas afinal, e a História? Qual sua contribuição para a prática?

Tal entendimento não pode de forma alguma estar desvinculado da compreensão do contexto da formação. Significativamente, o desenvolvimento da formação profissional na Educação Física brasileira foi pautada por este tipo de preocupação prática. E, mesmo que de maneira diferenciada, tal preocupação ainda persiste, embora existam consideráveis reflexões e movimentos contrários. Sem dúvida, esta concepção é uma das responsáveis por relegar à História uma restrita função e responsabilidade.

Isto é, se acharmos que a formação e a preparação profissional em nível superior tem o único intuito de apresentar fórmulas fechadas, soluções lineares, modelos de atuação a serem seguidos inquestionavelmente, a História tem realmente uma duvidável validade e relevância. Dentro desta perspectiva, suas funções se restringiriam à mera informação despretensiosa, 
um objeto de curiosidade, ou a distorcidamente justificar o presente.

Assim, não fica difícil compreender o desconforto existente. Desenvolve-se um imaginário em torno da disciplina, plenamente referendado pelo contexto da formação, que acaba por a relacionar a algo enfadonho ("porque tenho que decorar tantas datas e nomes'), completamente fora do contexto do curso ("eu não estou fazendo Educação Física para estudar história") e sem sentido por não ter aplicabilidade prática ("eu nunca vou usar essas coisas quando estiver trabalhando").

Veja bem que não estamos a dizer que a prática não é importante, mas sim que a graduação deve preparar para a atuação profissional não através de fórmulas e modelos fechados. A graduação deve dar condições, por meio de uma preparação teórica aprofundada, para que o aluno possa recriar constantemente sua atuação, a partir da compreensão da realidade que o cerca, dos valores em jogo, das especificidades da atuação e das possibilidades de que pode dispor para alcance de seus objetivos. A graduação estaria preocupada em preparar o aluno para pensar/ repensar sua atuação, entendendo que há a necessidade de uma compreensão teórica por trás de toda atuação, que nunca é só prática, mais indissociadamente teórico-prática.

Existiria nesta compreensão um outro sentido para a "História da Educação Física e do Esporte". Tal disciplina encontraria uma original possibilidade de contribuição, obviamente não mais podendo ser abordada segundo os ultrapassados padrões que ainda prevalecem.

Obviamente que não é possível discutir adequamente tal possibilidade de contribuição se não nos reportarmos aos domínios do campo de conhecimento da historiografia/Teoria da História. Basta considerar que a História da Educação Física e do Esporte não é em si Educação Física, mas História, que tem a Educação Física e o Esporte (e, diriam alguns, a cultura corporal de movimento), como objetos de pesquisa.

Assim, a disciplina "História da Educação Física e do 
Esporte" deveria fundamentalmente estar destinada a permitir ao aluno entender que é possível e necessário compreender historicamente a área de conhecimento, e, dando-lhe elementos para tal, levá-lo a considerar que tal entendimento é fundamental para sua práxis enquanto educador.

Deveria levar o aluno a compreender à efetiva atuação do homem na construção do mundo que o cerca, na transformação de sua sociedade. $O$ aluno precisa perceber que a história nos ajuda a entender que o homem tem/teve uma ação concreta: o que temos atualmente foi construído e não fruto exclusivo do acaso, tampouco estava escrito em um 'livro dos destinos'. Todos, querendo/sabendo ou não, fazemos parte da história. Ao mesmo tempo somos e fazemos história.

Mas também deve permitir ao aluno entender que isto não significa que tenhamos todas as possibilidades de fazermos a história da forma que desejamos e imaginamos. Existe uma série de barreiras, impedimentos, condicionantes sociais que muitas vezes nos impedem de plenamente seguir um caminho traçado. Dentro da prática social se apresentam outros caminhos, em um processo cotidiano do qual nem sempre tomamos consciência profunda.

Enfim, o passado também estabelece condicionantes. Condições a que temos de nos reportar no presente, situações construídas no decorrer do tempo. Assim, todos temos um passado que de alguma maneira influencia diretamente em nossas ações presentes. E o estudo da história nos ajuda a compreender melhor essas condições que nos cercam; as possíveis injunções do passado no presente.

Contudo, devemos ter cuidado para esclarecer aos alunos que isto não significa que exista uma relação linear e simplista de causa-conseqüência a ser desvendada. Muito pelo contrário, devemos tomar cuidado com esta compreensão. O presente não é a soma dos passados, guarda suas especificidades, seus próprios condicionamentos, que possivelmente só vamos poder entender melhor, pelo menos historicamente, em algum 
momento futuro. É inegável que o presente e o passado guardam uma relação, mas a História só está habilitada a 'lançar luz', auxiliar junto com outras disciplinas (Sociologia, Antropologia etc.) à busca de uma compreensão maior, sem a pretensão de estabelecer "verdades absolutas/inquestionáveis".

Também devemos tomar cuidado para esclarecer que o fato de buscarmos uma crítica do presente através do conhecimento histórico não significa, todavia, que a priori ela deva se submeter às compreensões ideológicas. A história tem um caminho para contribuir no entendimento da sociedade que se diferencia (e deve se diferenciar), embora não se negue a dialogar, de outros campos do conhecimento.

Não pode também ser descartada sua contribuição no conhecer e manter das tradições que se estabeleceram. Por si só, o patrimônio construído por nossos antepassados merece ser resguardado, inclusive pelo impacto que ocasiona na memória da sociedade. Além de sua contribuição, por sua própria natureza, no desenvolvimento e estímulo de forças transformadoras e questionadoras das estruturas sociais.

Logo, a disciplina "História da Educação Física e do Esporte" mais do que apresentar fatos e datas de forma descontextualizada ou desenvolver uma pseudo-crítica sobre tais fatos, deveria estar preocupada em oferecer ao aluno a possibilidade de aprender a compreender historicamente um problema, tendo como base as especificidades que ele irá encontrar em seu exercício profissional e como referência para desenvolver tal compreensão os elementos da crítica histórica colhidos no âmbito da historiografia/Teoria da História.

Por fim, se a pesquisa em História da Educação Física e do Esporte tem avançado muito, tal avanço não pode se limitar a pesquisa em si, devendo também ser incorporado no âmbito das disciplinas dos cursos de graduação, levando os alunos e futuros professores a perceberem melhor a importância do conhecimento histórico para sua práxis profissional.

Bem possivelmente, se os professores da disciplina 
incorporarem esta forma de pensar, aliada com estratégias pedagógicas adequadas, seu ensino se tornará mais agradável e sua importância mais reconhecida no contexto dos cursos de graduação em Educação Física.

\section{Referências bibliográficas}

FARIA JÚNIOR, Alfredo Gomes de. Professor de Educação Física, licenciado generalista. In: OLIVEIRA, Vitor Marinho de; FARIA JÚNIOR, Alfredo Gomes de (orgs.). Fundamentos Pedagógicos da Educação Física - 2. Rio de Janeiro: Ao Livro Técnico, 1987.

MELO, Victor Andrade de. Reflexão sobre a História da Educação Física no Brasil - uma abordagem historiográfica. Movimento, Porto Alegre, ano III, n. 4, p.41-48, 1996a.

. Escola Nacional de Educação Física e Desportos uma possível história. Campinas: Unicamp, 1996b. Dissertação (Mestrado em Educação Física). - Inezil Penna Marinho: notas biográficas. In:

FERREIRA NETO, Amarílio (org.). Pesquisa histórica na Educação Física - 3. Aracruz: FACHA, 1998. p.180-209.

PARK, Roberta J. Sport History in the 1990's: Prospects and problems. In: SAFRIT, Margaret J.; ECKERT, Helen M. The cutting edge in Physical Education and exercise science research. Champaign: Human Kinetics, 1987.

PINTOR, José Luiz Marques. A criação da Escola Nacional de Educação Física e Desportos da Universidade do Brasil e sua inserção na política do Estado Novo. Rio de Janeiro: UFRJ, 1995. Dissertação (Mestrado em Educação Física). 
ABSTRACT: This article has for purpose, since a comprehension of undergraduation courses, to argue about the importance of the schooling "History of Physical Education and Sport" in Physical Education undergraduation courses. While I discuss the current way of teaching this schooling, I intend to present an alternative to become more effective the contribution to undergraduate.

Keywords: Teaching History; History of Physical Education and Sport 


\section{ANEXO 1}

\section{HISTÓRIA DA EDUCAÇÃO FÍSICA E DO ESPORTE}

- Proposta de programa para disciplina de 60 horas -

1. A importância e a peculiaridade do estudo da História da Educação Física e do Esporte

1.1. O que é história? Como se estuda história? Conceitos básicos da pesquisa histórica.

1.2. Por que devemos estudar história nos cursos de graduação em EF?

1.3. História da História da Educação Física e do Esporte.

2. Aspectos históricos da Educação Física no Brasil e no mundo

2.1. O surgimento da Educação Física no cenário mundial

2.2. Os métodos ginásticos

2.3. O surgimento da Educação Física nas escolas brasileiras

\section{Aspectos históricos do esporte no Brasil e no Mundo}

3.1. O surgimento do campo esportivo no cenário mundial

3.2. Os Jogos Olímpicos

3.3. Os primeiros momentos do esporte no Brasil

4. Tópicos especiais em História da Educação Física e do Esporte

4.1. Formação profissional em Educação Física: aspectos históricos

4.2. Lazer e Educação Física no Brasil: relações históricas

4.3. Gênero, Educação Física e Esporte: aspectos históricos

4.4. A história recente da Educação Física brasileira

4.5. As associações científicas e o movimento estudantil em EF

4.6. História local, história familiar, Educação Física e esporte

Hist. Ensino, Londrina, v. 6, p. 91-101, out. 2000 